\title{
Views of internists towards uses of PGD
}

\section{Robert Klitzman, Wendy Chung, MD, PhD ${ }^{1}$, Karen Marder, MD ${ }^{1}$, Anita Shanmugham, MS $^{2}$, Lisa J. Chin, JD, EdD ${ }^{1,3,4}$, Meredith Stark, PhD $^{1}$, Cheng-Shiun Leu, PhD ${ }^{1}$, and Paul S. Appelbaum, MD $^{1,4}$}

Robert Klitzman: rlk2@columbia.edu; Wendy Chung:wkc15@columbia.edu; Karen Marder: kmarder@sergievsky.cpmc.columbia.edu; Anita Shanmugham: ans9105@nyp.org; Lisa J. Chin: ljc8@caa.columbia.edu; Meredith Stark: mgs2135@columbia.edu; Cheng-Shiun Leu: c194@columbia.edu; Paul S. Appelbaum: appelba@nyspi.columbia.edu

Professor of Clinical Psychiatry, Columbia University, 1051 Riverside Drive, Unit 15, New York, NY 10032, USA, Phone: 212-543-3710, Fax: 212-543-6003

${ }^{1}$ Columbia University (New York, New York, USA)

${ }^{2}$ New York-Presbyterian Morgan Stanley Children's Hospital (New York, New York, USA)

${ }^{3}$ HIV Center for Clinical and Behavior Studies

${ }^{4}$ New York State Psychiatric Institute (New York, New York, USA)

\section{Abstract}

Preimplantation genetic diagnosis (PGD) is increasingly available, but how physicians view it is unclear. Internists are gatekeepers and sources of information, often treating disorders for which PGD is possible. This quantitative study surveyed 220 US internists, who were found to be divided. Many would recommend PGD for cystic fibrosis (CF; 33.7\%), breast cancer (BRCA; 23.4\%), familial adenomatous polyposis (FAP; $20.6 \%$ ) and familial hypertrophic cardiomyopathy (19.9\%), but few for social sex selection (5.2\%); however, in each case, $>50 \%$ were unsure. Of those surveyed, $4.9 \%$ have suggested PGD to patients. Only $7.1 \%$ felt qualified to answer patient questions about it. Internists who would refer for PGD had completed medical training less recently and, for $\mathrm{CF}$, were more likely to have privately insured patients $(P<0.033)$ and patients who reported genetic discrimination $(P<0.013)$. Physicians more likely to refer for BRCA and FAP were less likely to have patients ask about genetic testing. This study suggests that internists often feel they have insufficient knowledge about it and may refer for it based on limited understanding. They view possible uses of PGD differently, partly reflecting varying ages of onset and disease treatability. These data have critical implications for training, research and practice.

(C) 2XXX Reproductive Healthcare Ltd. Published by Elsevier Ltd. All rights reserved.

Correspondence to: Robert Klitzman, rlk2@columbia.edu.

Columbia University: 1051 Riverside Drive, Mail Unit 15, New York, NY 10032, USA

New York-Presbyterian Morgan Stanley Children's Hospital: 3959 Broadway, 166th Street and Broadway, New York, New York, USA

HIV Center for Clinical and Behavior Studies, 1051 Riverside Drive, Mail Unit 15, New York, NY 10032, USA

New York State Psychiatric Institute, 1051 Riverside Drive, Mail Unit 15, New York, NY 10032, USA

Declaration: The authors report no financial or commercial conflicts of interest.

Publisher's Disclaimer: This is a PDF file of an unedited manuscript that has been accepted for publication. As a service to our customers we are providing this early version of the manuscript. The manuscript will undergo copyediting, typesetting, and review of the resulting proof before it is published in its final citable form. Please note that during the production process errors may be discovered which could affect the content, and all legal disclaimers that apply to the journal pertain. 


\section{Keywords}

assisted reproductive technology; ethics; IVF

\section{Introduction}

Preimplantation genetic diagnosis (PGD) appears to be increasingly utilized, but little is known about physician attitudes and practices concerning this technology. PGD is used in conjunction with IVF. Embryos, once formed in vitro may be biopsied at various stages for one or more cells. These biopsied samples are then analysed genetically and the measured outcomes assumed to be representative of the embryo from which they are taken. In this way couples at risk of transmitting serious genetic diseases to their offspring are enabled to commence a pregnancy without fear of carrying an affected fetus. While originally developed to be used for completely penetrant, monogenetic paediatric diseases, the scope and application for PGD has expanded in the past two decades to encompass screening for an array of heritable diseases as well as for other traits, including social sex selection (e.g. for family balancing) which has been controversial (Demko et al., 2010; Ogilvie et al., 2005; Hudson, 2006). In the USA, professional guidelines on indications for its use are lacking, and PGD is forbidden in many countries (Baruch et al., 2006).

Physicians, including internists, are gatekeepers and sources of information regarding use of medical technologies. Internists treat diseases that patients and their family members have or for which may be at risk. Hence, internists may have discussions with patients in which PGD as a new reproductive technology may be relevant. Indeed, internists are involved in treating patients who confront diseases for which PGD could be performed: e.g. breast cancer (BRCA; Brandt et al., 2010), familial adenomatous polyposis (FAP; Ao et al., 1998; Harper et al., 2010) and familial hypertrophic cardiomyopathy (FHC; Ogilvie et al., 2005). Consequently, internists' knowledge, attitudes and practices concerning PGD use are critical to understand.

Yet few studies have been conducted in this area have mostly examined views of specialists focused on reproductive issues (e.g. PGD providers and obstetrician/gynaecologists). Moreover, these studies have each tended to analyse use of PGD for only one or two indications: e.g. social sex selection (Puri and Nachtigall, 2010; Caldas et al., 2010) or BRCA (Brandt et al., 2010) among gynaecological oncologists and obstetricians and gynaecologists, and FAP (Moutou et al., 2007). A qualitative study of 19 US PGD service providers in diverse professions found 'concern about the quality of PGD' and about the lack of 'quality standards', but respondents widely endorsed using PGD to avoid severe lifethreatening illness, with greater variability for use for adult-onset disease or selection of non-medical traits such as sex (Kalfoglou, 2005).

For PGD for social sex selection, in qualitative interviews, 40 primary care physicians, including 25 obstetrician/gynaecologists, expressed more reservations, including ethical, social and policy concerns, than did the specialist sex-selection technology providers (Puri and Nachtigall, 2010). Gynaecological oncologists were less likely than obstetricians and gynaecologists to say that they would refer a patient for PGD testing ( $80 \%$ of gynaecological oncologists versus $91 \%$ of obstetrician and gynaecologists), perhaps related to the number of patients they see, although fewer in fact had done so (20\% versus $43 \%$; Brandt et al., 2010). In Brazil, 72\% of obstetrician/gynaecologists were in favour of PGD, although they varied on the suitability of the technology for sex selection (Caldas et al., 2010). In France, for PGD screening for cancers, 76 cancer geneticists and 30 members of multidisciplinary prenatal diagnosis teams, when asked about generic descriptions of broad 
categories of diseases with varying treatability, had high rates of acceptability for PGD use for childhood cancers, with lower rates of acceptability for adult-onset disease that were otherwise preventable and treatable (Julian-Reynier et al. 2009). This study also asked the cancer geneticists if they would find PGD acceptable for seven specific conditions and recorded that rates of acceptability ranged from Li-Fraumeni syndrome $(77.6 \%)$, retinoblasatoma $(76.3 \%)$, FAP $(72.4 \%)$, multiple endocrine neoplasia type $2(38.1 \%)$, neurofibromatosis-1 (47.3\%) and Lynch syndrome/hereditary nonpolyposis colorectal cancer $(27.7 \%)$ to BRCA1/2 (26.3\%; Julian-Reynier et al. 2009). Yet despite these studies, many gaps in knowledge remain. No quantitative studies have been conducted on attitudes among internists and general practitioners concerning use of PGD or on attitudes among any physicians concerning PGD for several of the conditions for which it is commonly used. Critical questions emerge as to whether internists have the knowledge necessary to make informed decisions about PGD and whether they have or would refer patients for PGD. Concerns have also arisen about genetic discrimination, that individuals who have been found to have certain genetic markers, but no symptoms or evidence of disease may encounter discrimination in employment or obtaining insurance (Klitzman 2012). Although the US Congress enacted the Genetic Information Nondiscrimination Act (GINA) in 2008, it covers health insurance, but not disability, life or long-term care insurance. Questions thus arise as to whether concerns about genetic discrimination or other factors may affect internists in their views of PGD.

\section{Materials and methods}

This study recruited internists who were members of departments of internal medicine at two medical centres. Invitations to participate in the survey were sent by email with a link to the survey instruments in July 2009 and two reminders were sent to all department members by email. Participants were offered a $\$ 5$ gift certificate at a national coffee store chain. The email lists contained approximately 993 and 110 addresses, respectively. Of 1103 names on the combined lists, 220 physicians responded, yielding a $19.9 \%$ response rate.

The survey instrument was a 44-item questionnaire accessible through the online survey system Survey Monkey (www.surveymonkey.com). The domains examined included physicians' personal and professional characteristics, characteristics of their patient population, attitudes and practices concerning genetic testing and PGD, and views of factors that may be involved with PGD and genetic testing (e.g. concerns about cost, insurance and discrimination). We pilot tested the survey with five clinicians first and revised accordingly prior to distribution.

Results from the survey were transferred from the Survey Monkey platform to a database for use in the Statistical Package for Social Sciences version 20 (SPSS, USA). Statistical analyses included chi-squared tests for examination of categorical variables and nonparametric statistics comparing medians for several Likert-scaled items that were treated as continuous variables. $P$-values were considered significant if $<0.05$.

As some of the 220 participants answered many, but not all of, the questions, calculations for each question are based on those participants who responded to that particular question.

The study was approved by the Institutional Review Board of New York State Psychiatric Institute (5 January 2012).

\section{Results}

As seen in Table 1, the sample was nearly evenly divided between males and females, with nearly half of respondents aged 30-39 and two-thirds having graduated from medical school 
after 1990. Of respondents, $4.9 \%$ reported having suggested PGD to a patient previously and only $7.1 \%$ felt qualified to answer patient questions about PGD.

Table 2 shows that physicians were divided as to whether they would recommend PGD for each of several different situations, with approximately half uncertain for all disorders. Rates of responses vary, however, by disease or indication listed. The highest percentage would suggest PGD for cystic fibrosis (33.7\%) and the lowest for social sex selection (5.2\%). Approximately half of physicians (49.4\%) would not recommend PGD for sex selection if it did not have medical implications (family history of X-linked disorder), with $45.4 \%$ unsure. For BRCA, FAP and FHC, 19.9\%, 23.4\% and 20.6\%, respectively, would refer a patient, but in each case more than half were unsure.

This study explored possible associations between physician characteristics (gender, ethnicity, decade completed medical school, having referred patients to genetic counsellors/ geneticists in the past 6 months and feeling qualified to answer PGD questions) and their stated willingness to order PGD for three most commonly endorsed conditions about which internists should have knowledge: CF, FAP and FHC. As seen in Table 3, those who would refer for PGD for CF were less likely to have completed medical training recently $(P=$ $0.029)$ and more likely to have more patients with private insurance $(P=0.033)$ and to have had patients who have reported genetic discrimination $(P=0.013)$. Those who were more likely to refer for BRCA were less likely to have completed medical school recently ( $P=$ $0.020)$ or to have had patients ask about genetic testing in the past 6 months $(P=0.005)$.

\section{Discussion}

This study, as far as is known the first to examine quantitatively attitudes and practices concerning PGD among internists, provides data about several issues. Internists feel they have insufficient knowledge about PGD and view the possible uses of PGD in different ways for conditions with different ages of onset, treatability and ethical concerns. Many respondents remain uncertain about how it should be used in any situation.

Of note, more than half of respondents are uncertain about when PGD should be recommended, even for disorders such as cystic fibrosis and DMD, where PGD is used relatively commonly, and for which, as childhood onset conditions that are chronic and ultimately lethal, ethical concerns are considered to be far less problematic. Clearly, needs exist to increase knowledge about PGD among internists.

Surprisingly, studies of specialists involved in reproductive issues have not examined attitudes towards several other indications probed here, such as HD, FAP, FHC and long QT syndrome.

In this exploratory analysis, it appeared that physician willingness to order PGD for four conditions (CF, FAP, FHC and BRCA) may be shaped by several factors and may reflect two separate phenomena: (i) understanding and (ii) lack of understanding of the issues involved. Physicians who would be willing to refer patients for PGD may feel more qualified to answer questions, but have had less exposure to genetics (as reflected in having completed medical training earlier or having fewer patients ask about genetic testing). Clearly, additional studies on larger samples of physicians are needed to investigate these issues and when, in fact, both groups of physicians (i.e. those with relatively more understanding versus less understanding of genetics) may refer patients for PGD.

This study has several implications for future research, highlighting needs to understand more fully how physicians make decisions about referral for PGD testing and what variables are involved related to characteristics of providers (e.g. year of medical school graduation), 
views (e.g. perceived disease burden, concerns about privacy, discrimination) and their patients (e.g. types of insurance). Future studies can explore these issues among physicians who are more senior or in other fields.

Clearly, internists' knowledge about PGD needs to be increased through training and continuing medical education. Although PGD can be controversial when used for social sex selection, it can also assist many patients in avoiding transmission of serious conditions to their offspring. Internists may treat patients and family members who confront a wide range of diseases for which PGD may be useful. Hence, it is important that these providers have some knowledge about the availability of this technology. Internists should be made aware of the technique, but also be taught to refer patients to clinical geneticists who could then refer patients to an IVF/PGD team, if needed, for additional information, specific details and help with decisions. Clearly, a multidisciplinary team is critical for a successful PGD programme. Given that genetic research is rapidly advancing and becoming more complex, internists cannot all be expected to have sophisticated understandings of all these areas, but should know to refer patients at risk of transmitting a genetic disease to a clinical geneticist to assist patients about their best reproductive options.

This study has several potential limitations. It included physicians from only internal medicine departments in two medical centres and the response rate was 19.9\%. However, this sample remains the largest to date of US internists concerning their views and practices regarding PGD, and this exploratory pilot study found several suggestive findings that can be probed further in future research. Moreover, response rates in studies have been declining steeply in recent years, both generally (Puri and Nachtigall, 2010) and especially among physicians (Brandt et al., 2010; Caldas et al., 2010). In addition, studies have suggested that low response rates do not necessarily result in non-response bias (Caldas et al., 2010), which may also be less of a concern in surveys of doctors, compared with surveys of the general public (Julian-Reynier et al., 2009; Kellerman and Harold, 2001). This study offered only a $\$ 5$ coupon as compensation, which may have contributed to the low response rate. Compared with physicians nationally, the respondents did not differ in ethnicity, but included more women (53.3\% versus $28.26 \%$ nationally; Runy, 2009). This difference might result from the fact that the study examined only internists, which include primary care physicians, who may be more likely to be female. For over 20 years, more women than men have entered family practice (Lambert and Holboe, 2005) and almost half of all primary care physicians are women (Tu and O'Malley, 2007). Other researchers have similarly obtained higher response rates from female than male primary care physicians concerning BRCA testing (Escher and Sappino, 2000). Of note several reports of doctor attitudes and practices regarding genetics did not mention participants' gender (Freedman et al. 2003; Grant et al., 2009; Lowstuter et al. 2008; Prochniak et al. 2011; Shields et al. 2008). Among physicians, women may be more concerned about these issues, although gender was not significantly associated with ordered genetic tests in the present study. These issues clearly warrant further examination in future research. The surveys also relied on self-reports; the extent of internists' knowledge and clinical experience concerning each of these diseases were not assessed. Due to the exploratory nature of this pilot study, adjustments for multiple comparisons were not made, but future studies can do so, and could explore these issues among larger samples as well, perhaps also examining physician records.

In summary, these data have critical implications, highlighting needs for future medical training and research to enhance physician understanding and practices concerning these increasingly important issues regarding PGD. 


\section{Acknowledgments}

The authors would like to thank Meghan Sweeney and Patricia Contino for their assistance with this manuscript. This research was funded by the National Human Genome Research Institute, Ethical, Legal and Social Implications Program (R-01-HG002431-01, 'Views of privacy of genetic information') and the National Human Genome Research Institute, Centre for ELSI Research on Psychiatric Neurologic and Behavioural Genetics (1P20HG005535-01).

\section{References}

Ao A, Wells D, Handyside AH, Winston RML, Delhanty JDA. Preimplantation Genetic Diagnosis of inherited cancer: familial adenomatous polyposis coli. J Assist Reprod Genet. 1998; 15(3):140-144. [PubMed: 9547690]

Baruch S, Kaufman K, Hudson KL. Genetic testing of embryos: practices and perspectives of US IVF clinics. Fertil Steril. 2006; 20(10):1-10.

Brandt AC, Tschirgi ML, Ready KJ, Sun S, Darilek S, Hecht J, Arun BK, Lu KH. Knowledge, attitudes, and clinical experience of physicians regarding preimplantation genetic diagnosis for hereditary cancer predisposition syndromes. Familial Cancer. 2010; 9:479-48710. [PubMed: 20431955]

Caldas GH, Caldas E, Araujo ED, Bonetti TCS, Leal CB, Costa AM. Opinions concerning preimplantation genetic diagnosis and sex selection among gynecologist-obstetricians in Brazil. European Journal of Obstetrics and Gynecology and Reproductive Biology. 2010; 148(2):158-162. [PubMed: 19926204]

Demko ZP, Rabinowitz M, Johnson D. Current methods for Preimplantation Genetic Diagnosis. Journal of Clinical Embryology. 2010; 13(1):6-12.

Escher M, Sappino AP. Primary care physicians' knowledge and attitudes toward genetic testing of breast-ovarian cancer predisposition. Annals of Oncology. 2000; 11(9):1131-1135. [PubMed: 11061607]

Freedman AN, Wideroff L, Olson L, Davis W, Klabunde C, Srinath KP, Reeve BB, Croyle RT, Ballard-Barbash R. U.S. physicians' attitudes toward genetic testing for cancer susceptibility. American Journal of Medical Genetics. 2003; 120A(1):63-71. [PubMed: 12794694]

Grant RW, Hivert M, Pandiscio JC, Florez JC, Nathan DM, Meigs JB. The clinical application of genetic testing in type 2 diabetes: a patient and physician survey. Diabetologia. 2009; 52(11):22992305. [PubMed: 19727660]

Harper JC, Coonen E, De Rycke M, Harton G, Motou C, Pehlivan T, Traeger-Synodinos J, Van Rij MC, Goossens V. ESHRE PGD consortium data collection X: cycles from January to December 2007 with pregnancy follow-up to October 2008. Hum Reprod. 2010; 25(1):2685-2707. [PubMed: 20813804]

Hudson KL. Preimplantation genetic diagnosis: public policy and public attitudes. Fertil Steril. 2006; 85(6):1638-1645. [PubMed: 16759921]

Julian-Reynier C, Chabal F, Freboug T, Lemery D, Nogues C, Puech F, Stoppa-Lyonnet D. Professionals assess the acceptability of preimplantation genetic diagnosis and prenatal diagnosis for managing inherited predisposition to cancer. J Clin Oncol. 2009; 27(27):4475-4480. [PubMed: 19704065]

Kalfoglou AL. PGD patients' and providers' attitudes to the use and regulation of Preimplantation genetic diagnosis. Reproductive BioMedicine Online. 2005; 11(4):485-496.

Kellerman SE, Harold J. Physician response to surveys. A review of the literature. Am J Prev Med. 2001; 20(1):61-67. [PubMed: 11137777]

Klitzman R, Chung W, Marder K, Shanmugham A, Chin LJ, Stark M, Leu CS, Appelbaum PS. Attitudes and practices among internists concerning genetic testing. J Genet Counsel. 201210.1007/s10897-012-9504-z

Lambert EM, Holboe ES. The relationship between specialty choice and gender of U.S. medical students, 1990-2003. Academic Medicine. 2005; 80(9):797-802. [PubMed: 16123456]

Lowstuter KJ, Sand S, Blazer KR, MacDonald DJ, Banks KC, Lee CA, Schwerin BU, Juarez M, Uman GC, Weitzel JN. Influence of genetic discrimination perceptions and knowledge on cancer 
genetics referral practice among clinicians. Genetics in Medicine. 2008; 10(9):691-698. [PubMed: 18978681]

Moutou C, Gardes N, Nicod J-C, Viville S. Strategies and outcomes of PGD of familial adenomatous polyposis. Molecular Human Reprod. 2007; 13(2):95-101.

Ogilvie CM, Braude PR, Scriven PN. Preimplantation genetic diagnosis - an overview. J Histochem Cytochem. 2005; 53(3):255-250. [PubMed: 15749997]

Prochniak CF, Martin LJ, Miller EM, Knapke SC. Barriers to and motivations for physician referral of patients to cancer genetics clinics. Journal of Genetic Counseling. 2011 Apr; 21(2):305-25. Epub 2011 Aug 13. [PubMed: 21842318]

Puri S, Nachtigall RD. The ethics of sex selection: a comparison of the attitudes and experiences of primary care physicians and physician providers of clinical sex selection services. Fertil Steril. 2010; 93(7):2107-2114. [PubMed: 19342036]

Runy, LA. Physician Snapshot: A Current and Future Look at Physician Demographics in America. Hospital and Health Networks. 2009. viewed 1 August 2012, http://www.hhnmag.com/ hhnmag_app/jsp/articledisplay.jsp?dcrpath=HHNMAG/Article/data/ 08AUG2009/0908HHN_FEA_Gatefoldanddomain=HHNMAG

Shields AE, Burke W, Levy DE. Differential use of available genetic tests among primary care physicians in the United States: results of a national survey. Genetics in Medicine. 2008; 10(6): 404-414. [PubMed: 18496223]

Tu, HT.; O'Malley, AS. Exodus of male physicians from primary care drives shift to specialty practice. Tracking Report No 17. 2007. viewed 1 August 2012, http://hschange.org/CONTENT/ 934/\#ib2

\section{Biography}

Robert Klitzman is a professor of clinical psychiatry at the Columbia University Department of Psychiatry. He is also the Director of the Ethics and Policy Core of the HIV Center for Clinical and Behavioral Studies at the New York State Psychiatric Institute and Department of Psychiatry and Director of the Masters of Bioethics Program at Columbia University. 
Table 1

Physician demographics and practices.

\begin{tabular}{ll}
\hline Characteristic & Sample $(\mathbf{n = 2 0 0})$ \\
\hline Gender & \\
Male & $46.7(100)$ \\
Female & $53.3(114)$ \\
Age (years) & \\
$20-29$ & $4.7(10)$ \\
$30-39$ & $45.3(97)$ \\
$40-49$ & $20.1(43)$ \\
$50-59$ & $15.0(32)$ \\
$60+$ & $15.0(32)$
\end{tabular}

Year of medical school graduation

$\begin{array}{ll}\text { Before } 1990 & 36.4(76) \\ \text { After } 1990 & 63.6(133)\end{array}$

Specialty

$\begin{array}{ll}\text { General medicine } & 18.7(40) \\ \text { Cardiology } & 14.5(31) \\ \text { Pulmonary/critical care } & 9.8(21) \\ \text { Digestive and liver disease } & 9.3(20) \\ \text { Haematology/oncology } & 8.4(18) \\ \text { Endocrinology } & 8.4(18) \\ \text { Nephrology } & 7.0(15) \\ \text { Infectious disease } & 3.3(7) \\ \text { Rheumatology } & 2.8(6) \\ \text { Other } & 17.9(38) \\ \text { Workplace setting } & \\ \text { Hospital-based } & 77.4(164) \\ \text { Community-based } & 8.5(18) \\ \text { Combination of above } & 14.2(30) \\ \text { MD ethnicity } & \\ \text { White } & 68.2(146) \\ \text { Asian/Pacific Islander } & 21.0(45) \\ \text { Hispanic } & 4.2(9) \\ \text { African-American } & 2.8(6) \\ \text { Other } & 3.7(8)\end{array}$

Have suggested PGD to a patient in the past

$\begin{array}{ll}\text { No } & 92.9(170) \\ \text { Yes } & 4.9(9) \\ \text { Not sure } & 2.2(4)\end{array}$

Feel qualified to answer patients' PGD questions No $90.7(165)$ 


\begin{tabular}{cl}
\hline Characteristic & Sample $(\mathbf{n}=\mathbf{2 0 0})$ \\
\hline Yes & $7.1(13)$ \\
Not sure & $2.2(4)$ \\
\hline
\end{tabular}

Values are \% (n). 


\section{Table 2}

Referral for PGD by disease outcome and for social sex selection.

\begin{tabular}{llll}
\hline Disease/indication & \multicolumn{2}{l}{ Referral for PGD } \\
\cline { 2 - 4 } & No & Uncertain & Yes \\
\hline Cystic fibrosis & $12.0(21)$ & $54.3(95)$ & $33.7(59)$ \\
Huntington's disease & $10.3(18)$ & $56.9(99)$ & $32.8(57)$ \\
Duchenne muscular dystrophy & $10.3(18)$ & $59.4(104)$ & $30.3(53)$ \\
Familial retinoblastoma & $11.0(19)$ & $64.2(111)$ & $24.9(43)$ \\
Familial adenomatous polyposis & $18.3(32)$ & $58.3(102)$ & $23.4(41)$ \\
Familial hypertrophic cardiomyopathy & $19.4(34)$ & $60.0(105)$ & $20.6(36)$ \\
Hereditary breast/ovarian cancer & $22.7(40)$ & $57.4(101)$ & $19.9(35)$ \\
Long QT syndrome & $22.3(39)$ & $59.4(104)$ & $18.3(32)$ \\
Type I diabetes & $33.0(58)$ & $56.3(99)$ & $10.8(19)$ \\
Inflammatory bowel disease & $32.4(56)$ & $61.3(106)$ & $6.4(11)$ \\
Sex selection (without medical implications) & $49.4(86)$ & $45.4(79)$ & $5.2(9)$ \\
\hline
\end{tabular}

Values are \% (n). 


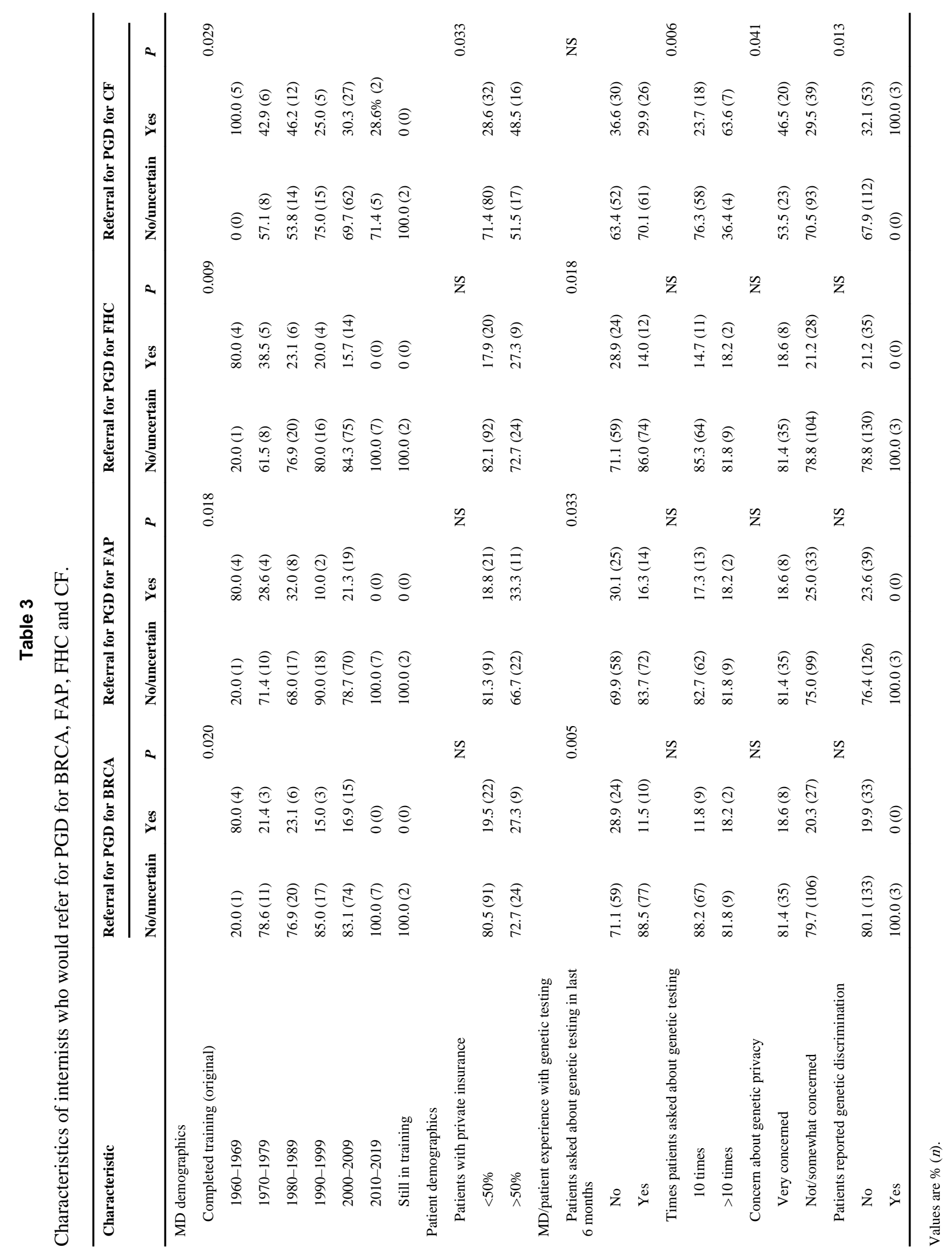


